\title{
Morphological Characteristics of Changes in the Duodenal Wall Within 14-56 Days of the Development of Streptozotocin-Induced Experimental Diabetes Mellitus
}

\author{
Ihor Bilinskyi $\mathbb{D}$
}

\begin{abstract}
The objective of the research was to determine the morphological features of the duodenal wall of animals within 14-56 days of developing streptozotocin-induced diabetes mellitus using light optical microscopy.

Materials and Methods. The research was carried out on 40 white nonlinear adult male rats. Diabetes mellitus was simulated by a single intraperitoneal injection of streptozotocin (Sigma, USA) at a dose of $60 \mathrm{mg} / \mathrm{kg}$ body weight. The material was taken from the duodenum on the $14^{\text {th }}, 28^{\text {th }}$ and the $56^{\text {th }}$ days after the onset of experimental diabetes mellitus. For histological study, the preparations were made using the conventional method, which included the staining of sections with hematoxylin and eosin.

Results. Streptozotocin-induced diabetes mellitus was experimentally found to lead to dystrophic changes in the epithelial components of the duodenal mucosa from the $14^{\text {th }}$ day of developing. There were observed a shortening of the villi of the mucous membrane and a lack of distinctness of striated border contours on the apical surface of epitheliocytes. Between the connective-tissue fibers of the lamina propria of the mucosa and thin-walled vessels, the cellular elements, including mainly macrophages, lymphocytes, were found. There was a shortening of the villi, edema and histiolymphocytic infiltration of the villous stroma 28 days after developing experimental diabetes mellitus. The epithelium covering was discontinuous; numerous areas of desquamation were found at the apex of the villi. Fifty-six days after developing experimental diabetes mellitus, the destruction and desquamation of the epithelium of the villi and crypts were observed. The surface of the duodenal mucosa smoothed down due to the shortening and flattening of the villi (indicating their atrophy), while the crypts elongated and their depth increased.

Conclusions. Histological study of the duodenal wall of diabetic animals showed pronounced desquamation at the apex of the villi, destructive and dystrophic changes in the surface epithelium, edema and increased cellular infiltration of the lamina propria of the mucosa. Thus, in diabetes mellitus, structural changes in the duodenal wall of rats are characterized by the dystrophic processes, which can be considered as the morphological reflection of enteropathy.
\end{abstract}

\section{Keywords}

Streptozotocin-Induced Diabetes Mellitus; Duodenum; Dystrophic Changes

Department of Clinical Anatomy and Operative Surgery, Ivano-Frankivsk National Medical University, Ukraine

Email: ibilinskuy@ifnmu.edu.ua

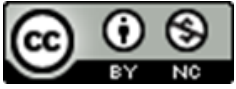




\section{Problem statement and analysis of the latest research}

According to the experts of the World Health Organization, $6-8 \%$ of the adult population suffer from diabetes mellitus (DM) and there is a tendency to the increase in DM incidence. $\mathrm{DM}$ is one of the three leaders among socially significant diseases remaing one of the most challenging health problems. In 2019, DM affected approximately 463 million people worldwide [1-4]. In the isolated experimental studies on type I DM, there has been found a close relationship between DM development and intestinal changes preceding clinical symptom onset $[5,6]$.

Gastrointestinal symptoms were observed in $92 \%$ of patients with DM [7]. Among clinical manifestations of DM, many researchers noted diabetic enteropathy. Microangiopathy and potential local restructuring of the intestinal wall played an important role in its development [8-10]. Recently, the interest of researchers in assessing the state of the duodenum in DM has significantly increased. The reason is the presence of clinically significant changes in the gastrointestinal tract in patients with DM, as well as the necessity to consider the effect of functional and morphological changes in the duodenum on metabolic processes in general [11-13, 16, 17].

Thus, the analysis of national and foreign literature showed that the problem of morphological features of the duodenal wall at different stages of developing DM is not fully studied and, therefore, seems relevant for the research.

The objective of the research was to determine the morphological features of the duodenal wall of animals within 14-56 days of developing streptozotocin (STZ)-induced DM using light optical microscopy.

\section{Materials and Methods}

The research was carried out on 40 white nonlinear male rats weighing 130-180 g, which were kept on a standard diet in the vivarium of the Ivano-Frankivsk National Medical University. The experimental rats were divided into two groups: Group 1 (the control group) included animals which were injected with an equivalent dose of $0.1 \mathrm{M}$ citrate buffer ( $\mathrm{pH} 4.5$ ) and Group 2 (the experimental group) comprised animals with STZ-induced DM. DM was simulated by a single intraperitoneal injection of STZ (Sigma, USA) at a dose of $60 \mathrm{mg} / \mathrm{kg}$ body weight. At the beginning of the experiment, before STZ was administered to the rats, blood was taken from the tail vein to determine blood glucose level by making superficial incisions in the tail region in the morning on an empty stomach. We used a portable blood glucose meter with a standard set of test strips (Accu-Chek Active, Roche Diagnostics, GH, Germany). The level of glycemia in the control and experimental groups was determined by glucose level. Only animals with a glucose level greater than $10.8 \mathrm{mmol} / \mathrm{l}$ were used in the experiment (Table 1). The sections of the duodenum served as the material for the study. The material was collected on the $14^{\text {th }}, 28^{\text {th }}$ and $56^{\text {th }}$ days after the onset of experimental
STZ-induced DM. For microscopic examination, tissue samples were fixed in $10 \%$ formalin solution, dehydrated in a series of alcohols, embedded in paraffin, sectioned in $\approx 5 \mu \mathrm{m}$ thick sections and stained with hematoxylin-eosin.

Computer processing of the parameters and data was performed by statistical methods using Microsoft Office Excel (Microsoft, USA, 2016) and Statistica 10.

Table 1. Glycemia level in the control and experimental groups at different stages of developing experimental STZ-induced DM (Mean \pm SD).

\begin{tabular}{ccc}
\hline $\begin{array}{c}\text { Term of the } \\
\text { experiment }\end{array}$ & Group of animals & Glucose, mmol/1 \\
\hline \multirow{2}{*}{$14^{\text {th }}$ day } & Control group & $4.78 \pm 0.57$ \\
& STZ-induced DM & $18.83 \pm 1.51^{*}$ \\
\hline \multirow{2}{*}{$28^{\text {th }}$ day } & Control group & $4.9 \pm 0.16$ \\
& STZ-induced DM & $19.01 \pm 1.88^{*}$ \\
\hline \multirow{2}{*}{$56^{\text {th }}$ day } & Control group & $5.02 \pm 0.17$ \\
& STZ-induced DM & $20.12 \pm 1.75^{*}$ \\
\hline
\end{tabular}

Note: probable difference as compared to the control group, Mann-Whitney U test, ${ }^{*} \mathrm{p}<0.05$.

\section{Ethical Statement}

All manipulations performed on the animals during the experiment did not contradict the regulations of the European Convention for the Protection of Vertebrate Animals used for Experimental and other Scientific Purposes (Strasbourg, 1986), the Council Directive 86/609/EEC (1986), the Law of Ukraine on the Protection of Animals from Cruelty of December 15, 2009 and the Orders of the Ministry of Health of Ukraine No 690 of September 23, 2009 and No 616 of August 03, 2012 and met the requirements of the Ethics Commission of the Ivano-Frankivsk National Medical University (Minutes No 104/18 of October 25, 2018).

\section{Results}

According to light microscopy, 14 days after the onset of STZ-induced DM, there was a slight flattening of the duodenal mucosa as compared to the control group. There was a slight shortening of the villi, while the crypt depth remained unchanged, and the crypt lumen expanded slightly (Fig. 1). There was an increase in the number of goblet cells, which contained a mucous secretion in the apical part. The cells had indistinct borders and the striated border on the apical side was occasionally absent. In addition, the cellular cytoplasm was amphiphilic, its enlightenment was noted; small transparent vacuoles were observed. The epithelium underwent similar transformation as well. The nuclei were round or oval, located basally both at the apex and the base of the villi, contained homogeneous chromatin.

Along with changes in the epithelium, the lamina propria of the mucosa underwent changes as well. At the apex of the villi, the connective-tissue fibers of the lamina propria 


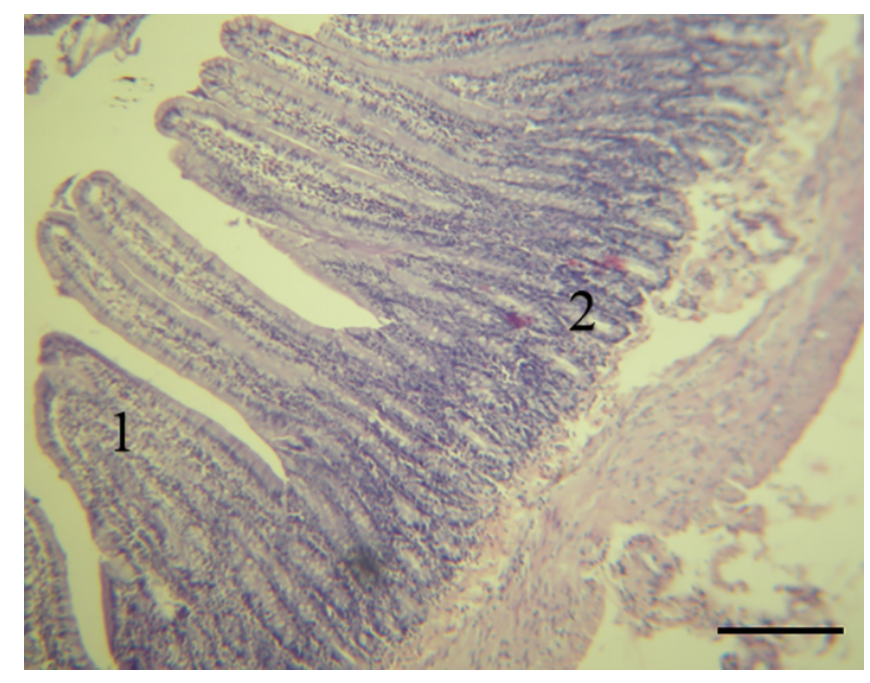

Figure 1. Shortening of the villi (1), expansion of the crypt lumen (2) in the duodenum 14 days after the onset of STZ-induced DM. Hematoxylin and eosin staining. Magnification: $\times 200$. Scale bar: $10 \mu \mathrm{m}$.

were loosely arranged; between them and thin-walled vessels, the cellular elements, including mainly macrophages, lymphocytes, eosinophilic granulocytes and single fibroblasts were found. The vessels of the lamina propria were thin-walled; a slightly pronounced arteriolar spasm with an uneven lumen expansion in the capillaries and postcapillary venules were occasionally observed. The vascular wall was lined with a single layer of endothelium; uniformly eosinophilic.

Both the lamina muscularis mucosae and the muscular membrane were represented by elongated smooth myocytes with homogeneous eosinophilic cytoplasm and oval nuclei. Between the layers of the muscular membrane, there were thin layers of loose connective tissue with single cellular elements, including macrophages, lymphocytes and fibroblasts. The submucosa of the duodenal wall was formed by loose connective tissue and contained the secretory units of the duodenal glands. Light microscopy revealed no structural changes in the cells of the terminal segments of these glands.

At the end of the $28^{\text {th }}$ day of STZ-induced DM, histological study revealed more significant changes in the structure of the duodenal mucosa. There was observed a shortening of the villi; their stroma was swollen and infiltrated with leukocytes; the epithelium covering was discontinuous; the areas of desquamation were found at the apex of the villi (Fig. 2).The crypt depth decreased; the crypt lumen expanded. The surface epithelium of the mucous membrane was characterized by amphiphilic, slightly enlightened and partially vacuolated cytoplasm. Changes in cell size with the cytoplasm increasing in size, were accompanied, on the contrary, by the decrease in nuclear size as a reflection of the degenerative processes. The number of goblet cells increased as compared to the previous group. Among the cells of the connective-tissue villous stroma, the cellular elements, including fibroblasts, numer- ous lymphocytes and macrophages predominated. The vessels of the lamina propria of the mucous membrane demontrated a mosaic pattern of the disruption of blood supply with the expansion of the venules and narrowing of the arteries in hemomicrocirculation. In the arterial portion, the wall was homogeneous, eosinophilic, with circularly elongated endothelial cells, slightly evenly thickened.

There were found no pronounced morphological changes in smooth myocytes of the duodenal muscular membrane. In the secretory units of the duodenal glands, acidophilic cells and mucous cells were unchanged.

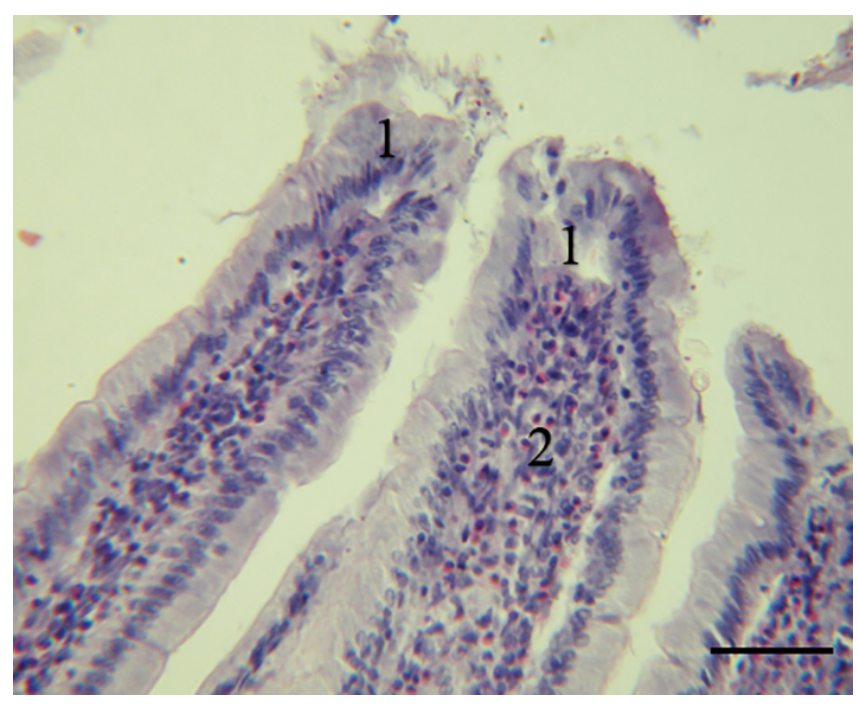

Figure 2. Areas of epitheliocyte desquamation at the apex of the villi (1), edema and histiolymphocytic infiltration of the villous stroma in the duodenal wall (2) 28 days after the onset of experimental STZ-induced DM. Hematoxylin and eosin staining. Magnification: $\times 400$. Scale bar: $10 \mu \mathrm{m}$.

Fifty-six days after the onset of STZ-induced DM, we found destructive and dystrophic changes in the surface epithelium of the duodenal wall (Fig. 3). There was observed the desquamation of the surface epithelium on most of the villi. Partial loss of the striated border and enlightened amphiphilic cytoplasm were evident in epitheliocytes. The basally located nuclei were round, contained homogeneous chromatin; its slight compaction was observed. The reduction in the mucous membrane was characterized by changes in both the length of the villi and the depth of the crypts. There was a further shortening of the villi and a decrease in their width, elongation of the crypts and increase in their depth. The lamina propria of the duodenal mucosa was characterized by an increase in cellular infiltration, a significant increase in the number of lymphocytes, plasma cells, tissue basophils, mostly on the apex of the villi. In the crypt lumen, an accumulation of the mucus and necrotic cells of the surface epithelium was found. The vessels of the lamina propria of the mucosa and the submucosal layer had the signs of uneven mosaic vascularization manifested as decreased blood supply to the venules 


\section{Morphological Characteristics of Changes in the Duodenal Wall Within 14-56 Days of the Development of Streptozotocin-Induced Experimental Diabetes Mellitus - 4/6}

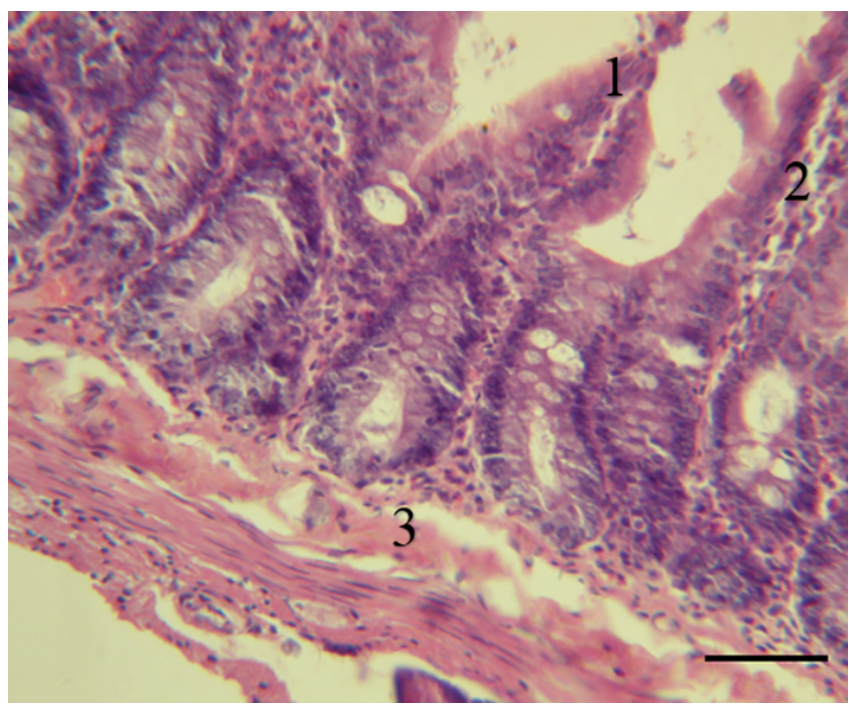

Figure 3. Destruction of the villi (1), histiolymphocytic infiltration of the villous stroma (2), edema of the interstitium of the lamina propria of the duodenal mucosa (3) 56 days

after the onset of experimental STZ-induced DM.

Hematoxylin and eosin staining. Magnification: $\times 200$. Scale bar: $10 \mu \mathrm{m}$.

and a pronounced narrowing of the arteries. The individual vessels were unevenly thickened, with a homogeneous eosinophilic wall.

Smooth myocytes of the lamina muscularis mucosae and the muscular membrane were elongated; the cytoplasm was homogeneous eosinophilic, non-vacuolated; the nuclei were oval with homogeneous chromatin and a clear nuclear membrane.

\section{Discussion}

The complications caused by DM (including diabetic enteropathy) are becoming increasingly common $[6,9,16]$. Gotfried $\mathrm{J}$ et al. indicated that the latest scientific results are promising, but there is still a need for further studies on the pathogenesis and morphological changes in the intestinal wall in diabetic enteropathy [14].

Histological study of the duodenal wall under the influence of experimental DM revealed significant structural changes mainly in the epithelial components of the mucous membrane.

Fourteen days after the development of experimental STZinduced DM, there were observed a slight shortening of the villi in the duodenal mucosa, an increase in the number of goblet cells; cells with indistinct borders were found; the ciliated border on the apical side was occasionally absent. Similar changes in the duodenal mucosa were found in rats with skin burn in experimental STZ-induced DM [15]. The vessels of the lamina propria were thin-walled; a pronounced arteriolar spasm with lumen expansion in the capillaries was observed which was consistent with the studies conducted by Onysko RM et al. [18].
Twenty-eight days after the development of experimental STZ-induced DM, there were observed a shortening and flattening of the mucosal villi with the destruction and desquamation of the epithelium, crypt elongation and increase in their depth. There was an increase in the number of goblet exocrinocytes. Similar changes were found in the small intestine of rats with chronic enterocolitis in experimental DM [11], which was most likely due to the development of microangiopathy and metabolic disorders. Among the cells of the villous stroma, fibroblasts, numerous lymphocytes and macrophages predominated. The cells of the villous epithelium increased in size due to uneven vacuolation; increased basophilia of their cytoplasm was seen; the striated border was occasionally not defined. The vessels of the lamina propria of the mucous membrane were characterized by the expansion of the venules and narrowing of the arteries in hemomicrocirculation that was confirmed by the study on the peculiarities of changes in the microstructural organization of tissues and hemomicrocirculatory bloodstream in the small intestine of rats at different stafes of developing experimental STZinduced DM conducted by Onysko RM et al. [18].

Fifty-six days after the onset of STZ-induced DM, further villous shortening and crypt elongation were observed; the phenomena of diffuse histiolymphocytic infiltration of the villous stroma progressed. The shift of the nuclei of epitheliocytes located basally towards the apical side of the cells, creating a picture of pseudo-stratification of the single-layered villous epithelium, was found. There was observed loose connective tissue swelling in the lamina propria. In the duodenal mucosa, hemodynamic disturbances in the form of edema and uneven vascular congestion were registered. These conclusions corresponded to the conclusions made by Lisnyanska NV et al., Onysko RM et al. [11, 18], which was most likely due to abnormal processes of restoring the integrity of the endothelial and epithelial layers, the decrease in the number of endothelial cells and their dysfunction.

According to the study of morphological changes in the duodenal mucosa at different stages of developing STZ-induced DM, the dystrophic and destructive processes in the duodenal wall were more pronounced than adaptive ones, manifested themselves as capillary lumen expansion and enterocyte hypertrophy. According to the results of our research, histological study of the duodenal wall revealed the deformation and destruction of the villi and crypts, numerous areas of dystrophy and necrosis of columnar epitheliocytes, swelling and enlightenment of loose connective tissue of the lamina propria of the mucosa, histiolymphocytic infiltration of the villous stroma. The results obtained were consistent with the results obtained by Lisnyanska NV et al., Krivonosova EM, Silvia Pellegrini et al., Onysko RM et al. [11-13, 18].

Changes in the structural components of the duodenal mucosa of rats at different stages of developing experimental STZ-induced DM we identified significantly deepened the understanding of reconstructing the intestinal wall in hyperglycemia being the morphological basis for understanding 
the pathogenesis and clinical course of diseases caused by DM.

\section{Conclusions}

Histological study of the duodenal wall of diabetic animals showed significant dystrophic and destructive changes.

1. Fourteen days after the onset of experimental DM, a slight shortening of the villi and the expansion of the crypt lumen were observed. There were found changes in columnar epitheliocytes with the striated border in the vilus covering: there was a shift of the nuclei located basally towards the apical side of the cell. The number of goblet cells increased both in the villi and in the crypts.

2. Twenty-eight days after the development of experimental STZ-induced DM, more significant changes in the structure of the duodenal mucosa were detected by histological study. There was observed a shortening of the villi; their stroma was swollen and infiltrated with leukocytes; the epithelium covering was discontinuous; numerous areas of desquamation were visualized at the apex of the villi. Swelling and enlightenment of loose connective tissue of the lamina propria of the mucosa were found.

3. Fifty-six days after the onset of STZ-induced DM, a shortening and flattening of the mucosal villi was observed indicating their atrophy, while the crypts elongated, their depth increased; consequently, the surface of the duodenal mucosa smoothed down. The destruction and desquamation of the epithelium of the villi and crypts were observed. The cells of the villous epithelium increased in size due to uneven vacuolation; increased basophilia of their cytoplasm was seen. There was found diffuse histiolymphocytic infiltration of the villous stroma.

\section{Conflict of Interest}

The authors declare that no conflicts exist.

\section{Financial Disclosure}

The authors declared no financial support.

\section{References}

[1] Meldgaard T, Olesen SS, Farmer AD, Krogh K, Wendel AA, Brock B, et al. Diabetic Enteropathy: From Molecule to Mechanism-Based Treatment. Journal of Diabetes Research [Internet]. 2018 Sep 16;2018:1-12. Available from: https://doi.org/10.1155/2018/3827301

[2] Kuźnik E, Dudkowiak R, Adamiec R, Poniewierka E. Diabetic autonomic neuropathy of the gastrointestinal tract.
Gastroenterology Review [Internet]. 2020;15(2):89-93. Available from: https://doi.org/10.5114/pg.2020.95554

[3] Wang L, Shang Q, Guo W, Wu X, Wu L, Wu $\mathrm{L}$, et al. Evaluation of the hypoglycemic effect of probiotics via directly consuming glucose in intestines of STZ-induced diabetic mice and glucose water-induced diabetic mice. Journal of Functional Foods [Internet]. 2020 Jan;64:103614. Available from: https://doi.org/10.1016/j.jff.2019.103614

[4] IDF. IDF DIABETES ATLAS 9th edition 2019. Available from: https://www.diabetesatlas.org/en/

[5] Cherkasov VG, Tymoshenko IO. Structural changes of duodenal mucosa enterocytes of rats in burn skin injury under experimental streptozotocin-induced diabetes mellitus. Reports of Morphology [Internet]. 2019 Feb 28;25(1):55-61. Available from: https://doi.org/10.31393/morphology-journal-201925(1)-08

[6] Bulum T. Gastrointestinal Complications of Diabetes. Ann Clin Diabetes Endocrinol. 2018;1(1):1001. Available from: http://www.remedypublications.com/openaccess/pgastrointestinal-complications-of-diabetesp1999.pdf

[7] Maisey A. A Practical Approach to Gastrointestinal Complications of Diabetes. Diabetes Therapy [Internet]. 2016 Jul 18;7(3):379-386. Available from: https://doi.org/10.1007/s13300-016-0182-y

[8] Zhong H-J, Yuan Y, Xie W-R, Chen M-H, He X-X. Type 2 Diabetes Mellitus Is Associated with More Serious Small Intestinal Mucosal Injuries. PLOS ONE [Internet]. 2016 Sep 6;11(9):e0162354. Available from: https://doi.org/10.1371/journal.pone.0162354

[9] Hugh T. Circulating factors implicated in diabetic enteropathy. Nature Reviews Gastroenterology \& Hepatology [Internet]. 2015 Oct 20;12(12):671-671. Available from: https://doi.org/10.1038/nrgastro.2015.183

[10] Boland BS, Edelman SV, Wolosin JD. Gastrointestinal Complications of Diabetes. Endocrinology and Metabolism Clinics of North America [Internet]. 2013 Dec;42(4):809-832. Available from: https://doi.org/10.1016/j.ecl.2013.07.006

[11] Lisnianska NV, Marushchak MI, Holovatiuk LM, Orel YM. State of the small intestine at chronic enterocolitis combined with streptozotocin-induced diabetes in rats: pathobiochemical data. Achievements of Clinical and Experimental Medicine. 2017 Nov 2;1(3):105111. Available from: https://doi.org/10.11603/18112471.2017.v1.i3.8172 
[12] Krivonosova E. Morphological and functional mucous layer condition of stomach and duodenum in patients with diabetes mellitus. Journal KhNU [Internet]. 2006;(13):35-39. Available from: https://periodicals.karazin.ua/medicine/article/view/7073

[13] Pellegrini S, Sordi V, Bolla AM, Saita D, Ferrarese R, Canducci F, et al. Duodenal Mucosa of Patients With Type 1 Diabetes Shows Distinctive Inflammatory Profile and Microbiota. The Journal of Clinical Endocrinology \& Metabolism [Internet]. 2017 Jan 19;102(5):1468-1477. Available from: https://doi.org/10.1210/jc.2016-3222

[14] Gotfried J, Priest S, Schey R. Diabetes and the Small Intestine. Current Treatment Options in Gastroenterology [Internet]. 2017 Sep 15;15(4):490-507. Available from: https://doi.org/10.1007/s11938-017-0155-X

[15] Tymoshenko I. Structural characteristics of the rat duodenal mucosa during burn injury to the skin under the conditions of experimental streptozotocinin-induced diabetes mellitus. Ukrainian Scientific Medical Youth Journal [Internet]. 2019 Apr 5;(1(109)):35-47. Available from: https://doi.org/10.32345/USMYJ.1(109).2019.35-47
[16] Yarmolenko OA, Malaeva EG, Hudyakov IA, Menshakova MN, Kobruseva LA. Diabeticheskaya enteropatiya. Problemyi zdorovya i ekologii. 2018;3(57):70-74. Available from: http://elib.gsmu.by/handle/GomSMU/3941

[17] Dorofieiev AE, Shvets NI, Parkhomenko TA, Dynia YuZ, Chychula YuV. Diabetychna enterokolopatiia v patsiientiv iz tsukrovym diabetom 2-ho typu. Mizhnarodnyi endokrynolohichnyi zhurnal. 2019;15(1):61-65. Available from: http://www.mif-ua.com/archive/article/47342

[18] Onysko RM, Paltov YeV, Breidak YuH, Kryvko YuIa. Osoblyvosti zmin mikrostrukturnoi orhanizatsii tkanyn ta lanok hemomikrotsyrkuliatornoho rusla tonkoi kyshky shchuriv na riznykh terminakh perebihu eksperymentalnoho streptozototsynindukovanoho tsukrovoho diabetu. Praktychna medytsyna: nauk.-prakt. zhurnal. 2011;18(3):42-58.

Received: 2020-09-07

Revised: $2020-10-14$

Accepted: 2020-11-16 